Clauson, S., Hollins Martin, C.J., Watt, G. (2012). Anxiety as a cause of attachment avoidance in women with Turner Syndrome. Sexual and Relationship Therapy. 27(4):

377-390. http://dx.doi.org/10.1080/14681994.2012.748891

Sarah Clauson ${ }^{1} \mathrm{BSc}$

Caroline Hollins Martin² PhD MPhil BSc ADM PGCE RMT RM RGN MBPsS

Gordon Watt ${ }^{3}$ FCPodMed MChS DPodM Cert FE

${ }^{1}$ School of Health, Glasgow Caledonian University, UK

${ }^{2}$ Professor in Midwifery, School of Nursing, Midwifery and Social Care, University of Salford, Greater Manchester, UK

${ }^{3}$ School of Health, Glasgow Caledonian University, UK

Address for correspondence: Caroline J. Hollins Martin, MS2.78, Mary Seacole Building, University of Salford, Greater Manchester. E-mail: $\underline{\text { C.J.Hollins-Martin@salford.ac.uk }}$ 


\title{
Anxiety as a cause of attachment avoidance in women with Turner Syndrome
}

\begin{abstract}
Working models of attachment are internal depictions of self relative to others and have been described in terms of two dimensions: (1) attachment avoidance, and (2) attachment anxiety. An exploratory qualitative study was carried out to build understandings about women with Turner Syndrome (TS) and the psychosocial impact their infertility has upon salient relationships. In one-to-one semi-structured interviews five women with TS were asked: How do you perceive your womanhood and infertility status has affected your relationships with the: (1) opposite sex, (2) siblings, and (3) peers. In opposite sex relationships, infertility status was found to arouse fear of ending up alone and anxiety over engaging in romantic relationships. In sibling relationships, jealousy was expressed in relation to disparity with sister(s) more natural maturation to womanhood, and within peer relationships consequences from divulging infertility status created attachment avoidance with friends. Further investigation in this area is merited.
\end{abstract}

Keywords: Turner Syndrome, infertility, attachment, avoidance, anxiety 


\section{Anxiety as a cause of attachment avoidance in women with Turner Syndrome}

\section{Introduction}

Turner Syndrome (TS) affects around 1 in every 2500 women (Carel et al., 2006). The condition occurs as a consequence of an XO chromosome organization that results in progression to either Classic TS or Mosaic TS, dependant upon whether all or part of the $23^{\text {rd }}$ second $X$ chromosome is missing (Loesch et al., 2005). Individuals with TS develop ovarian dysgenesis, which halts normal pubertal development (Frias \& Davenport, 2003). As a consequence the gonads are dysfunctional, with oestrogen prescribed in early teenage life to induce puberty (National Institute of Clinical Excellence, 2002). Egg donation and invertro fertilization are the only potential means of a woman with TS conceiving (Lippe, 1991). As a consequence of their infertility status, little is known about how women with TS perceive their availability and worth to others in terms of meaningful relationships. Differences between women with TS and other infertile women are that they know from diagnosis that they are barren, whilst the majority of infertile others acknowledge their infertility status at the end of failed treatment processes. Having knowledge from outset as a child of these differences may affect relationship engagement and attachment processes made with significant others. Increasing knowledge in this area may alert counsellors, family and TS women themselves about possible attachment issues.

\section{What is attachment?}

According to Bowlby (1988), working models of attachment are internal depictions of self relative to others. These internal representations result from experiences in relation to significant others, e.g., opposite sex, siblings and friends (Creasy \& Ladd, 2005; Fraley, 2007). Internal models of attachment have been described in terms of two dimensions:

(1) attachment avoidance, and (2) attachment anxiety (Gillath et al., 2005; Noftle \& Shaver, 2006). Individuals with low avoidance and low anxiety are considered to be securely attached to others, which incorporates feeling at ease with closeness, intimacy and 
dependency, and trust of selected others. In contrast, people with high anxiety and high avoidance consider that they are unlovable and that others are untrustworthy and rejecting. These individuals tend towards protecting themselves against anticipated rejection by avoiding close involvement with others. It has been argued that high avoidance interferes with constructing close and intimate relationships with others (Scuse et al., 1994; Shaver et al., 2005; Sibley \& Liu, 2006). This article considers whether women with TS experience attachment difficulties within opposite sex, siblings and peer relationships, as a perceived consequence of their unusual progression to womanhood and infertility status? The focus of this article is on avoidance and anxiety of women with TS in relation to developing relationships with the opposite sex, siblings and peers.

\section{Literature review}

Prior research reveals that attachment avoidance influences an increase in interpersonal difficulties (Bartholmew \& Horowitz, 1991; Horowitz et al., 1993). Significantly, there are indications that for women with TS, infertility is an instigator of hesitancy to engage in relations with the opposite sex, with reasons still unclear (McCauley \& Sybert, 2006; Rolstad et al., 2007; Sutton et al., 2005; Verlinde et al., 2004). Also, in general women with TS encounter their first sexual experience later in life (Boman et al, 1998; Carel et al., 2006; Rolstad et al., 2007; Spira et al., 1993) and have fewer sexual partners than their non TS peers (Boman et al., 1998; Naess et al., 2010; Rolstad et al., 2007).

Other psychological studies have documented behaviour patterns in women with TS that involve social withdrawal (Downey et al., 1989; McCauley et al., 1986; Williams., 1994). Awkwardness with interactions, reduced assertiveness and the resulting social isolation has been shown to promote overprotection from parents (Ross et al., 2000), which may compliment an already reduced interest in exposure to people outside the family. Behavioural profiles differ by age, with younger girls with TS described as more hyperactive and anxious, with anxiety, depression and unsatisfactory relationships more typical of older girls (McCauley et al., 1994). 
Women with TS do not report a high prevalence of severe psychopathology, with emotional disturbance and poor adjustment instead ascribed (Christopoulos et al., 2008). In general, women with TS describe themselves as more sensation seeking (Collin, 2006), less detached, less verbally aggressive and less irritated compared with non TS peers (Christopoulos et al., 2008). To date, no research has reported on sibling relationships and lack of clarity in reports about specific thoughts that cause anxiety and attachment avoidance in relation to opposite sex and peer relationships, justifies solicitation of a research method that acts in a conscience-raising manner. Such appreciation will raise awareness of counsellors, parents and women with TS themselves about potential psychosocial impact their womanhood and infertility can have upon motivating relationship development. With this in mind, the objective was to explore the association between progression to womanhood of women with Turner Syndrome (TS) and affects upon attachments in interpersonal relationships.

\section{Method}

An exploratory qualitative study was carried out to build understandings about women with TS and the psychosocial impact their womanhood and infertility has upon motivating relationship development. This research focuses on answering a broadly stated question about individual viewpoints, which unlike deductive quantitative reasoning may generate many answers. Developed conceptualizations will arise from actual narratives of the informants. The exploratory nature of the method permits the researcher to focus more precisely on informants' experiences. The approach utilises a naturalistic inquiry, with focus on perception rather than experience. The importance of the qualitative method is to give voice to women with TS, without manipulation or forced influence about a matter that directly affects their personal wellbeing. This approach assumed that the underlying essence of meaning would emerge through the reflective description of the informant's world (Roche, 1973; Strauss \& Corbin, 1990). Verbal expression of accounts could be fixed in text, where the meaning intended by the speaker can be located (Klemm, 1983). The principles of 
comparative analysis were used to elicit and clarify meaning from interview transcripts (Ragin, 1987). This research focuses on a particular group of women with specific anxieties, with the selected approach permitting exploration of issues that otherwise would be difficult to understand through statistical based techniques. In a shift away from the positivist approach to scientific enquiry and towards the interpretive sciences, a number of scholars recommend that the qualitative approach is suitable to acquiring depth of knowledge (Roche, 1973; Strauss \& Corbin, 1990).

\section{Informants}

Within a qualitative method, sample size depends greatly upon the testimonies of the individuals involved and the richness of the data. This means the number of research informants can be very low. For the purpose of this pilot study, a decision was taken to limit the number of informants with view to undertaking greater depth of enquiry. A purposive sample of five women from the Turner Syndrome Support Society (TSSS) with Classic TS (complete deletion of an X chromosome in all cells) aged $20-40$ consented to be informants in the study.

\section{Ethical approval}

Ethical approval was acquired from Glasgow Caledonian University (GCU) School of Health ethics committee. Approval and permission was also attained from the Executive Officer of the TSSS. Informed consent was obtained from informants prior to study inclusion and permission for audio recording sought.

\section{Interviews}

Potential informants were telephoned and the study process explained. One-to-one interviews were carried out. Five semi-structured interviews were conducted within the School of Health at Glasgow Caledonian University. Participants were afforded anonymity and confidentiality. Written consent was obtained and audio recordings made available post event. Procedures were informal and amorphous to permit greatest flow of information. The 
semi-structured interview schedule contained the following questions. The choice of questions was informed by the literature review.

Literature has identified that infertility is an instigator of hesitancy in women with TS to engage in opposite sex relations, with reasons still unclear (McCauley \& Sybert, 2006; Rolstad et al., 2007; Sutton et al., 2005; Verlinde et al., 2004). Also, encounters of first sexual experience often occur later in life (Boman et al, 1998; Carel et al., 2006; Rolstad et al., 2007; Spira et al., 1993), with fewer sexual partners than non TS peers (Boman et al., 1998; Naess et al., 2010; Rolstad et al., 2007). In an attempt to find out more about attachment issues surrounding opposite sex relationships, question one was framed:

(1) How do you perceive your womanhood and infertility status has affected your relationships with the opposite sex?

The literature identified that awkwardness with interactions, reduced assertiveness and resulting social isolation has promoted overprotection from parents (Ross et al., 2000). It was considered that these factors may affect relationships with brothers and sisters. In an attempt to find out more about siblings relationships, question two was framed:

(2) How do you perceive your womanhood and infertility status has affected your relationships with siblings (brothers and sisters)?

Other literature has documented that women with TS can socially withdraw (Downey et al., 1989; McCauley et al., 1986; Williams., 1994). In an attempt to find out more about attachment issues surrounding peer relationships, question three was framed:

(3) How do you perceive your womanhood and infertility status has affected your relationships with peers?

These relatively broad questions identified the initial focus of inquiry and aimed to attain depth of understanding. To achieve this, information was gathered to inform these broad questions. The broad questions were then refined using more specific questions, which led to more focused information-gathering as the study progressed. This meant the research questions evolved in a cyclical manner, rather than following one after another in a stepwise sequence. The aim and objectives created the starting point from which evidence 
in the report showed what was learned from the research encounter. Questions were asked and prompts given. For example: Can you provide an example? How would you go about this? Could you elaborate on that? Informants could make as many (or as few) comments as they liked.

\section{Data analysis}

Interviews were transcribed verbatim. All transcripts were read in entirety to assist engagement and generate interpretation from an initial sense of participants' stories. The rationale was to identify preliminary codes. The coding procedure was based on that developed by Charmaz, who suggests open coding line by line, which although rigorous, helps to reduce researcher influence and bias. Short descriptive labels were allocated to sections of the text, following which labels expressing similar concepts were grouped together to form themes. Labels and themes were compared across transcripts. The allocated codes enabled the researcher to summarise and synthesise the data. During the writing process, literature was used to support the allotted labels and their properties. The selected quotes reflect themes that unravel the women with TS perceptions of the affects their atypical womanhood and infertility status had upon their relationships with others.

\section{Trustworthiness}

To verify trustworthiness of the study design, three central issues are considered important; credibility, transferability and dependability (Koch, 1994). Inter-rater reliability was substantiated by the two researchers who conducted the data analysis for purpose of lessening possibility of researcher bias during theme development. The ultimate category system produced was agreed by both researchers and accepted as being representative of the data. Researcher impartiality was disclosed from the outset, with biases or assumptions that may influence inquiry established. 


\section{Findings and discussion}

Themes and sub-themes generated from the qualitative analysis are outlined in Table 1:

\section{TABLE 1}

Each of the themes is discussed before concluding that women with TS have depth of feeling associated with their womanhood. Findings of the study highlight different ways informants have experienced their womanhood and infertility status, with reports of how it has affected relationships duplicated by sometimes more than two of the interviewees. Findings may be used by counsellors, parents and women with TS themselves to develop insight into experiences that may be encountered by other women with TS. Findings are conscience-raising and serve to extend awareness of lived experiences of women with TS in three sets of social relationships; opposite sex, siblings and peers.

\section{Opposite sex relationships}

The theme opposite sex relationships consists of two sub-themes and is concerned with the informants' experiences of infertility in relation to partnering with men. The two sub-themes include:

\section{Fear of ending up alone}

Informant five did not express desire to avoid relationships with men, but clearly experienced anxiety about forming intimate relations. The infertility issue was reported to be causal:

"I am more nervous because of the fertility side of it. If you were in a serious relationship you would need to explain that at some point and that would be quite hard" (Informant 1).

In this statement, anxiety about raising the issue of infertility with potential partners was highlighted. Although prior literature has shown that some women with TS do not engage in intimate relations with men (McCauley \& Sybert, 2006; Rolstad et al., 2007; Sutton et al, 2005; Verlinde et al., 2004), none have discussed abstinence in relation to attachment anxiety and avoidance. The following two informants believed that their infertility status would deter male interest: 
"I guess because of my insecurity and low self-esteem. I felt that if I lost that person then that was it. There would never be anyone else. So I knew I couldn't say straight off, I don't want children" (Informant 3).

"When I was younger my confidence and self esteem were so poor that I believed that even if I didn't want to get involved with someone who showed interest in me, I should because no one else was ever going to" (Informant 2).

Both informants subscribe to the concept of self esteem. In some studies, adolescents with TS have reported similar challenges to instigating relationships with men (Suzigan et al., 2004), which can lower self esteem (Sybert \& McCauley, 2004; McCauley et al., 2001; Killic et al, 2005). Within pre-existing literature, again links with anxiety and avoidance are not discussed. Fear of ending up alone was expressed by the following informant:

"If I wasn't careful then I would end up alone and I was frightened of that" (Informant 4).

Informant five's comment is extremely relevant to counsellors, with the issue of avoiding relationships and fear arousal a potential area of interest.

"I would like to start a family, but obviously the fertility side of it all is not going to be easy. He needs to understand it more" (Informant 5).

It is important to stress that the majority of women with TS present as regular looking, have conventional personalities, customary manners and social skills, are impassioned and can be expected to live long and healthy lives. An emphasis on "difference" can obscure the fact that women with TS and those without are more similar to one another than different. The majority can, and do, live rich and rewarding lives. It is possible for a woman with TS to host and deliver an infant through fertility treatment. Solutions involve egg donation and fertilisation using the partner's sperm, which is technically known as In-Vitro Fertilisation (IVF). Some of the comments made indicate a perception of disinterest from the opposite sex, which lies unsupported in that many women with TS successfully mate pair for life. 


\section{Anxiety over engaging in sexual relationships}

All five informants expressed that they felt more inexperienced in sexual matters compared with their non TS peers:

"I was also very naïve. I didn't have the same levels of experience that my friends had in relationships" (Informant 2).

"I kinda still feel naive around men. Like l've got a lot to learn, even about myself, compared to my friends" (Informant 1).

Four out of the five informants used the word naïve when discussing sexual matters. Again anxiety appears to create hesitancy and in some cases avoidance of actively engaging in relationships with men, with naivety about sex inescapable due to lack of experience in comparison to sexually active peers of the same age. The literature has shown that women with TS often encounter their first sexual experience later in life (Boman et al., 1998; Carel et al., 2006; Rolstad et al., 2007; Spira et al., 1993) and have fewer sexual partners than their non TS peers (Boman et al., 1998; Naess et al., 2010; Rolstad et al., 2007).

"I was more in my thirties before I really considered getting into one or even wanted to be in one (romantic relationship). Cause I think there was a considerable amount of naivety there and I was unsure of what to do" (Informant 3).

"My longest relationship only lasted for three years. But even then I was still very shy and naive. People thought I had all this experience, but in reality I didn't have a clue" (Informant 4).

"I think l'd struggle. l'd be like really nervous and l'd be like really unconfident if I was to like went out and met someone. I wouldn't like know what to do to" (Informant 5).

Four attachment styles have been identified in adult relationships: secure, anxiouspreoccupied, dismissive-avoidant and fearful-avoidant. Securely attached adults hold positive views of self, their partners and their relationships. They are at ease with both intimacy and independence, harmonizing the two. Anxious-preoccupied adults request 
elevated levels of intimacy, approval and responsiveness from their partners and often become over dependent. These quotes are not expressing this particular style of attachment. Instead, they are more reflective of dismissive-avoidant adults who desire elevated levels of independence and as such the women with TS appear to avoid attachment altogether. They have a tendency to suppress their feelings and deal with rejection through distancing themselves from potential partners. Fearful-avoidant adults hold mixed feelings about having close relationships, often desiring and being uncomfortable with emotional closeness simultaneously. They often mistrust their partners and view themselves as unworthy. Akin to dismissive-avoidant adults, fearful-avoidant adults tend to seek less intimacy and suppress their feelings (Bartholomew \& Horowitz, 1991; Hazan \& Shaver, $1987,1990,1994)$. Also of interest, is the perceived affects of atypical sexual development upon sibling relationships.

\section{Sibling relationships}

The theme sibling relationships consists of one sub-theme and is concerned with the informants' perceived relationship with sibling sisters as a consequence of their womanhood. The one sub-theme includes:

\section{Jealousy of sister(s) more natural maturation to womanhood}

Two informants reported that they felt jealous of their female siblings more natural maturation to womanhood.

"I was jealous of my sisters, 'cause it was the fact that they were developing as women. 'Cause they've all got massive boobs than me, massive boobs, where as I had none" (Informant 4).

"I do still get jealous because I feel that I haven't been able to share that important passage of life that a women should go through" (Informant 3).

Bartholomew and Horowitz (1991) proposed that working models of attachment consist of two parts. Part one refers to thoughts about self and part two considers thoughts about others. They further propose that a person's thoughts about self are generally positive 
or negative. The same applies to a person's thoughts about others. In the statements made about personal development in relation to secondary sexual characteristics, which without hormonal input is absent in girls with TS, thoughts about self were shown to be negative. This is illustrated through use of the word jealousy. In contrast, evaluation of sisters' development of secondary characteristics is being viewed as positive. Sisters' developing physical sexual attributes and comparison of self as different can effect self esteem and create negative sociability in terms of Anxious - Preoccupied, according to Bartholomew and Horowitz (1991). Overall this emotional state can effect sociability and thoughts about others.

In an exploratory study by Williams (1995), mothers of girls with TS reported that their daughters had issues coping with lack of breast development. Absence of secondary sexual characteristics in women with TS (Christopoulos et al., 2008) can hinder progress through the normal adolescent developmental stages (Dunkel \& Sefcek, 2009). Specifically, the quality interpersonal relationships required for appropriate psychosocial development and constructing a sense of "self" and "identity" (Kagan-Krieger, 2008).

Jealousy is in varying degrees a normal experience for young children (Volling et al., 2002). However, possible constructions of self and identity that cause anxiety and avoidance of romantic relationships that sisters do not face may accentuate sibling jealousy.

\section{Peer relationships}

The theme peer relationships consists of two sub-themes and is concerned with the informants' perceived relationships with friends as a direct consequence of their womanhood and infertility status. The two sub-themes included:

\section{Problems with trust about divulging infertility position}

Within peer relationships, avoidance was related to problems with discretion and trust about divulging the informants' TS status and its style of development to womanhood and infertility position. This situation clearly created anxiety, which resulted in careful selection of a group of discrete and trustworthy friends. The following informant expressed that trust was a key 
issue when forming attachments with friends.

"It wasn't until I was nearly completing secondary school that I felt able to trust and really share with anyone that I had TS. But at that it was only with three of the girls within my class that I could really trust" (Informant 3).

Williams (1995) describes how six mothers of girls with TS reported that their daughters had difficulties initiating and maintaining peer relationships. This was in part ascribed to difficulties with their daughters' modifying their physical appearance to be consistent with peers. Some researchers cite experiential and environmental factors, such as rejuvenilization, heightism and overprotective parenting as accentuators in development of psychological problems in girls with TS (Christopoulos et al., 2008). In this instance anxiety and avoidance of forming relationships with peers.

\section{Cautious selection of a small trustworthy group of friends}

Three informants' hesitancy to share "their reality" resulted in assembly of a limited circle of trusted female friends:

"I've made a really small group of close friends at Uni. I think I prefer a smaller group of people, rather than a large group of friends. It is easier to explain to a few close friends (about TS). They are all girls which kinda helps" (Informant 5).

"Only as I got to know the girls that I was in the class with, I started to sort of tell one or two of them. Only a certain few of the girls knew about the Turners and the fertility side of it, because I felt that it was, it is, something that is quite private and I don't really want everybody knowing" (Informant 1).

"I was never in what you would call a clique of friends. I had a couple of girl friends, but that was it" (Informant 4).

The documented problems of social isolation and a tendency to have a passive, over compliant and non assertive personality (McCauley et al., 1986,1987; Money \& Mittenthal, 1970; Rovet, 1992) and poor body image (Downey et al., 1989), may be an associated side of anxiety avoidance disorder, although the relationship has never fully been explored and explained. What is worthy of note, is that relationships formed through peer relationships can 
influence gain in social skills, intellectual development and configuration of social identity. Classification of children's peer status (popular, neglected or rejected) has been shown to predict consequent adjustment (Shaffer, 2007). Insecure children, particularly avoidant children, are particularly susceptible to family risk. Their subsequent social and behavioural difficulties escalate or decline with deterioration or improvement in parenting skills. An early secure attachment has a lasting protective function (Berlin et al., 2008). Bearing similarity to attachment with parental figures, subsequent experiences can modify course of development (Berlin et al., 2008).

\section{Study limitations}

The small number of informants allowed greater depth of analysis. Whilst this limits generalisabiity of the study findings, it has allowed the researchers to identify an area that deserves further research attention. It was considered that attachment anxiety and avoidance might influence interpersonal interactions from the origins of a TS diagnosis, with further study recommended to investigate what might reduce anxiety and facilitate forming attachments to significant others.

\section{General discussion}

This small study has emphasized that anxiety is high in some women with TS in relation to forming attachments with the opposite sex and peers. To date, no studies have specifically focused on assessing and attempting to reduce anxiety of women with TS in relation to attachment. What other studies have provided, is evidence of outcomes rather than process. For example, individuals with TS are usually older when they have their first sexual experience (Boman et al., 1998; Carel, 2006; McCauley et al., 1994; Pavlidis et al., 1995; Rolstad et al., 2007), which is consistent with what some of our informants' stated. What is apparent is that the psychological determinants remain unclear. Also women with TS are less likely to establish a steady relationship and are generally less sexually active than their non TS contempories (Boman et al., 1998; Naess et al., 2010; Pavlidis et al., 1995; Rolstad et al., 2007). Pavlidis et al. (1995) reported that out of $(n=80)$ women, only $55 \%$ reported 
having sexual relations by the age of 34 . Carel et al. (2006) testimonies that by the age of 20 only $30 \%$ of women with TS have had sexual experience compared with $85 \%$ of the general population (Spira et al., 1993). Further investigation of the psychological processes leading to these outcomes is required, with findings having the potential to aid counselors, parents and girls with TS towards a positive transition to adulthood. Anxiety and avoidance of attachments may be just one of the myriad of precursors that lead to avoidance of sexual relations.

The fact that some informants expressed interest in having relationships, at the same time as avoiding them, shows potential for resolve. For example, Hess (2002) discusses strategies that facilitate individuals to increase or decrease their psychological distance from others. Distance increasing strategies include: (1) Perceiving dissimilarity between the individual and an interaction partner, (2) Showing interpersonal negative feelings, (3) Hiding information about one's self, and (4) Disregarding the other's messages. On the contrary, distance reducing strategies include: (1) Perceiving similarity between the individual and an interaction partner, (2) Showing interpersonal positive feelings, (3) Showing an intension or willingness to share things about one's self, and (4) acknowledging or considering the partner's message.

It is important to reiterate to counselors, parents and girls with TS that it is now possible for a woman with TS to have child. Processes involve egg donation and fertilisation using the partner's sperm. The donated eggs and sperm are amalgamated in a test tube, with typical fertilisation resulting 12-15 hours later. The fertilised eggs are referred to as preembryos and an agreed number (usually 2-3) are placed into the uterus about two days post egg collection from the donor. The pre-embryo(s) are subsequently transferred through the cervix into the uterus using a file. In preparation, hormone treatment is given to prepare the lining of the uterus for embryonic embedding. Due to limited success, such knowledge may not affect a reduction anxiety.

In addition to anxiety and avoidance about engaging in opposite sex relationships, this study also highlights a previously unreported finding of jealousy in relation to sisters 
more natural maturation to womanhood. Childhood jealousy, often defined as sibling rivalry, frequently surface in clinical and paediatric texts (Leung \& Robson, 1991; Neubauer, 1983; Parrot, 1991). What prior research has shown is that sibling rivalry arises from competition for parental attention and a need for love and approval, which can be affected by having special children in the family (Sparrow, 2005).

Friendship avoidance and anxiety to form attachments may in part be augmented by difficulties some women with TS have with reading social cues (Bender et al., 1989; Gordon \& Galatzer, 1980; Silbert et al., 1977), and deficits in understanding how to effectively interact with others (Siegel et al., 1998).

\section{Conclusion and recommendations}

This paper acts in a conscience-raising manner intended to extend knowledge of some of the experiences women with TS have with attachment in salient relationships. A more generalised understanding may increase willingness of women with TS to disclose their anxieties to counselors, parents, friends and men. In doing so, exploration, discussion and resolve are more likely. Clearly, some women with TS are more affected by their diagnosis than others, and some are better able to cope with related difficulties. What is apparent is that the study informants are at the same time very similar and different to non TS women with reproductive difficulties. Their experiences of relationships echo the voices of many others who experience infertility, with the major difference being that infertility status is known from the outset.

\section{Declaration of Conflicting Interests}

The author(s) declared no potential conflicts of interest with respect to the authorship and/or publication of this article.

\section{Funding}

The author(s) received no financial support for the research and/or authorship of this article. 


\section{References}

Bartholmew, K., \& Horowitz, L. M. (1991). Attachment styles among young adults: a test of a four category model. Journal of Personality and Social Psychology, 61, 226-244.

Berlin, L.J., \& Cassidy, J. \& Appleyard, K. (2008). The influence of early attachments on other relationships. In: Cassidy, J. \& Shaver, P.R. Handbook of Attachment: Theory, Research and Clinical Applications. New York and London: Guilford Press. pp. 333-47.

Bender, B., Linden, M., \& Robinson, A. (1989). Verbal and spatial processing efficiency in 32 children with sex chromosome abnormalities. Pediatric Research, 25, 577-579.

Bowlby, J. (1988). A secure base: Clinical applications of attachment theory. London: Routledge.

Boman, U., Moller, A., \& Albertsson-Wikland, K. (1998). Psychological aspects of Turner syndrome. Journal of Psychosomatic Obstetrics and Gynecology, 19, 1-18.

Carel, J., Elie, C., Ecosse, E., Tauber, M., Léger, J., Cabrol, S., Nicolino, M., Brauner, R., Chaussain, J. L., \& Joël Coste, J. (2006). Self-esteem and social adjustment in young women with Turner Syndrome: influence of pubertal management and sexuality: population-based cohort study. Journal of Clinical Endocrinology and Metabolism, 91(8), 2972-2979.

Charmaz, K. (2006). Constructing grounded theory: a practical Guide through qualitative analysis. Thousand Oaks, CA: Sage

Christopoulos. P., Deligeoroglou, E., Laggari, V., Christopoulos, S., \& Creatsas, G. (2008). Psychological and behavioural aspects of patients with Turner syndrome from childhood to adulthood: a review of the clinical literature. Journal of Psychosomatic Obstetrics and Gynecology, 29(1): 45-51.

Collin, J. (2006). An introduction to Turners Syndrome. Paediatric Nursing, 18(10), 38-43.

Creasy, G., \& Ladd, A. (2005). Generalised and specific attachment representations: unique and interactive roles in predicting conflict behaviours in close relationships. Personality and Social Psychology Bulletin, 31, 1026-1038.

Downey, J., Ehrhardt, A., Gruen, R., Bell, J., \& Morishima, A. (1989). Psychopathology and social functioning in women with Turner syndrome. Journal of Nervous and Mental Disease, 177, 191-201.

Dunkel, C.S., \& Sefcek, J.A. (2009). Eriksonian lifespan theory and life history theory:an integration using the example of identity formation. Review of General Psychology, 13(1), 13-23.

Fraley, R.C. (2007). A connectionist approach to the organisation and continuity of working models of attachment. Journal of Personality and Social Psychology, 75, 1157-1180.

Frias, J.L., \& Davenport, M.L. (2003). Health supervision for children with Turner Syndrome. American Academy of Paediatrics, 111(3), 692-702. 
Gillath, O., Shaver, P. R., Mikulincer, M., Nitzberg, R. E., Erez, A., \& Van Ijzendoorn, M. H. (2005). Attachment, caregiving, and volunteering: Placing volunteerism in an attachment theoretical framework. Personality Relationships, 12, 425-445.

Gordon, H., \& Galatzer, A. (1980). Cerebral organization in patients with gonadal dysgenesis. Psychoneuroendocrinology, 5, 235-244.

Gravholt, C. H., Svenstrup, B., Bennett, P., \& Sandahl Christiansen, J. (1999). Reduced androgen levels in adult Turner syndrome: influence of female sex steroids and growth hormone status. Clinical Endocrinology, 50, 791-800.

Hazan, C. \& Shaver, P.R. (1987). Romantic love conceptualized as an attachment process. Journal of Personality and Social Psychology, 52(3): 511-24.

Hazan, C. \& Shaver, P.R. (1990). Love and work: an attachment theoretical perspective. Journal of Personality and Social Psychology, 59(2): 270-80

Hazan, C. \& Shaver, P.R. (1994). Attachment as an organisational framework for research on close relationships. Psychological Inquiry, 5: 1-22.

Hess, J.A. (2002). Distance regulation in personal relationships. The development of a conceptual model and a test of representational validity. Journal of Social and Personal Relationships, 19, 663-683.

Horowitz, L.M., Rosenberg, S.E., \& Bartholmew, K. (1993). Interpersonal problems, attachment styles, and outcome in brief dynamic psyvchotherapy. Journal of Personality and Social Psychology, 61, 549-560.

Kagan-Kreiger, S. (1998). Brief report: women with Turner syndrome: a maturational and development perspective. Journal of Adult Development. 5(2), 125-135.

Kesler, S. R. (2007). Turner Syndrome: child and adolescent psychiatric clinics of North America. Neuropsychiatric Genetic Syndromes, 16(3), 709-722.

Kiliç, B. G., Ergür, A. T., \& Ocal, G. (2005). Depression, levels of anxiety and self-concept in girls with Turner's syndrome. Journal of Paediatric Endocrinology and Metabolism, 18(11), 1111-7.

Klemm, D. E. (1983). The hermeneutical theory of Paul Ricoeur. Associated University Presses, New Jersey.

Koch, T. (1994). Establishing rigour in qualitative research: the decision trail. Journal of Advanced Nursing. 19, 976-986.

Leung, A., \& Robson, W. (1991). Sibling rivalry. Clinical Pediatrics, 30, 314-317.

Lippe, B. (1991). Turner Syndrome: endocrine metabolic clinics of North America. 30, 121152.

Loesch, D. Z., Bui, Q. M., Kelso, W., Huggins, R. M., Slater, H., \& Warner, G. (2005). Effects of Turners Syndrome and X-linked imprinting on cognitive status: analysis based on pedigree data. Brain and Development. 27(7), 494-503. 
McCauley, E., Feuillan, P., Kushner, H., \& Ross, J. L. (2001). Psychosocial development in adolescents with Turner syndrome. Journal of Development Behavioural Pediatic. 22, 360-365.

McCauley, E., Ito, J., \& Kay, T. (1986). Psychosocial functioning in girls with Turner's Syndrome and short stature: social skills behavior problems, and self concept. Journal of the American Academy of Child Psychiatry, 25, 105-112.

McCauley, E., Kay, T., Ito, J., \& Treder, R. (1987). The Turner syndrome: cognitive deficits, affective discrimination, and behaviour problems. Child development, 58, 464-473.

McCauley, E., Ross, J., \& Sybert, V. (1994). Self concept and behavioural profiles in Turner Syndrome. In: Stabler, B, Underwood, L. (Eds.). Growth Stature and Adaptation. The University of Carolina, Chapel Hill, pp. 181-193.

McCauley, E., \& Sybert, V. (2006). Social and behavioral development of girls and women with Turner Syndrome. International Congress Series, 1298, 93-99.

Miller, K. K. (2001). Androgen deficiency in women. Journal of Clinical Endocrinology and Metabolism, 86, 2395-2401.

Money, J., \& Mittenthal ,S. (1970). Lack of personality pathology in Turner's syndrome: relation to cytogenetics, hormones and physique. Behavior Genetics, 1, 43-56.

Naess, E. E., Bahr, D., \& Gravholt, C. H. (2010). Health status in women with Turner Syndrome: a questionnaire study on health status, education, work participation and aspects of sexual functioning. Journal of Clinical Endocrinology, 72(5), 678.

National Institute for Clinical Excellence (NICE) (2002). Guidance on the use of human growth hormone (somatropin) in children with growth failure. NICE, London.

Neubauer, P. B. (1983). The importance of sibling experience. Psychoanalytic Study of the Child, 38, 325-336.

Noftle, E. E., \& Shaver, P. R. (2006). Attachment dimensions and the big five personality traits: Associations and comparative ability to predict relationship quality. Journal of Research in Personality, 18, 199-221.

Parrot, W. G. (1991). The emotional experiences of envy and jealousy. In: Salovey, P. (Ed.). The psychology of jealousy and envy. Guilford, New York, pp. 3-30.

Pavlidis, K., McCauley, E., \& Sybert, V. P. (1995). Psychosocial and sexual functioning in women with Turner Syndrome. Clinical Genetics, 47, 85-89.

Ragin, C. (1987). The comparative method: moving beyond qualitative and quantitative strategies. Los Angeles: University of California Press.

Rolstad, S.G., Moller, A., Bryman, I., \& Boman, U.W. (2007). Sexual functioning and partner relationships in women with Turner syndrome: some empirical data and theoretical considerations regarding sexual desire. Journal of Sexual and Marital Therapy, 33(3), 231-247.

Roche, M. (1973). Phenomenology, language and the social sciences. Boston: Routledge and Kegan Paul. 
Ross, J., Zinn, A., \& McCauley, E. (2000). Neurodevelopmental and psychosocial aspects of Turner Syndrome. Mental Retardation and Developmental Disabilities. Research Reviews, 6(2): 135-141.

Rovet, J. (1992). The pseudoeducational characteristics of children with Turners Syndrome. Contemporary Pediatrics, 3(2), 13-21.

Scuse, D., Percy, E.L., \& Stevenson, J. (1994). Psychosocial functioning in the Turner Syndrome: a national survey. In: Stabler, B., Underwood, L. E. (Eds.). Growth, stature and adaptation. University of North Carolina, Chapel Hill NC, pp. 151-164.

Schaffer, R. (2007). Introducing Child Psychology. Oxford: Blackwell. pp. 83-121.

Shaver, P.R., Schachner, D. A., \& Mikulincer, M. (2005). Attachment style, excessive reassurance seeking, relationship processes, and depression. Personality and Social Psychology Bulletin, 31, 343-359.

Sibley, C.G., \& Liu, J.H. (2006).Working models of romantic attachment and the subjective quality of social interactions across relational contexts. Personal Relationships. 13, 243259.

Silbert, A., Wolff, P., \& Lilienthal, J. (1977). Spatial and temporal processing in patients with Turner's Syndrome. Behavioral Genetics, 7, 11.

Siegel, P., Clopper, R., \& Stabler, B. (1998). The psychological consequences of Turner Syndrome and review of the national cooperative growth study psychological sub study. Pediatrics, 102, 488-491.

Sparrow, J. (2005). Understanding Sibling Rivalry: The Brazelton Way. Boulder CO: Da Capo Press.

Spira, A., Bajos, N., \& Le groupe, A. (1993). Les comportement sexuels en France. Paris: La Documentaion Française.

Strauss, A., \& Corbin, J. (1990). Basics of qualitative research. Newbury Park, CA: Sage.

Sutton, E., Mclnerney-Leo, A., Bondy, C., Gollust, S., King, D. \& Biesecker, B. (2005). Turner Syndrome: four challenges across the lifespan. American Journal of Medical Genetics, 139(2), 57-66.

Suzigan, L., Silva, R., Lemos- Marini, S., Baptista, M., Guerr, G. \& Magna, A. (2004). Turner Syndrome: the patients' view. Journal of Paediatrics, 80, 309-14.

Sybert, V. \& McCauley, E. (2004). Turner's Syndrome. The New England Journal of Medicine, 351, 1227-1238.

Verlinde, F., Massa, G., Lagrou, K., Froidecoeur, C., Bourguignon, J., \& Craen, M. (2004). Health and psychosocial status of patients with Turner Syndrome after transition to adulthood: the Belgian experience. Hormone Research, 62(4), 161-7.

Volling, B., McElwain, N., \& Miller, A. (2002). Emotional regulation in context: the jealousy complex between young siblings and its relations with child and family characteristics. Child Development, 73(2), 581-600. 
Williams, J. (1994). Behavioral characteristics of children with Turner syndrome and learning disabilities. Western Journal of Nursing Research, 16, 26-39.

Williams, J. (1995). Parenting a daughter with precocious puberty of Turners Syndrome. Pediatric Health Care, 9, 109-114. 
Table 1. Themes and sub-themes of reported experiences of TS women about perceived effects their infertility had on significant relationships?

Themes Sub-themes

Opposite sex relationships Fear of ending up alone

Anxiety over engaging in sexual relationships

Sibling relationships Jealousy of sister(s) more natural maturation to womanhood

Peer relationships

Problems with trust about divulging infertility position

Cautious selection of a small trustworthy group of friends 